\title{
Palinotaxonomia de espécies de Apocynaceae ocorrentes na Restinga de Carapebus, Carapebus, RJ, Brasil ${ }^{1}$
}

\author{
Fábio de França Moreira², Cláudia Barbieri Ferreira Mendonça ${ }^{1,2}$, Jorge Fontella Pereira² e Vania Gonçalves-Esteves ${ }^{2}$
}

Recebido em 26/09/2003. Aceito em 24/03/2004

\begin{abstract}
RESUMO - (Palinotaxonomia de espécies de Apocynaceae ocorrentes na restinga de Carapebus, Carapebus, RJ, Brasil). Neste trabalho foram tratadas, palinologicamente, 11 espécies de Apocynaceae pertencentes a sete gêneros, ocorrentes na restinga de Carapebus, situada no litoral norte do Estado do Rio de Janeiro. As espécies tratadas foram: Aspidosperma parvifolium A. DC.; Forsteronia leptocarpa (Hook. \& Arns.) A. DC.; Himatanthus lancifolius (Müll. Arg.) Woodson; Mandevilla fragrans (Stadelm.) Woodson; Mandevilla sp.; M. moricandiana (A. DC.) Woodson; M. tenuifolia (J.C. Mikan) Woodson; Prestonia coalita (Vell.) Woodson; Rhabdadenia pohlii Müll. Arg.; Tabernaemontana flavicans Willd. ex Roem. \& Schult.; T. laeta Mart. Os grãos de pólen foram tratados pelo método da acetólise láctica, medidos, descritos e ilustrados sob microscopia de luz e microscopia eletrônica de varredura. Os resultados obtidos mostraram que dois grandes grupos podem ser identificados: grãos de pólen colporados - Aspidosperma parvifolium (5-6-colporados, exina psilada, rugulada apenas no apocolpo), Himatanthus lancifolius (3-colporados, exina reticulada), Tabernaemontana flavicans (4-colporados, endoabertura endocingulada) e T. laeta (3-4-colporados, exina rugulada); grãos de pólen porados - Forsteronia leptocarpa, as quatro espécies de Mandevilla, Prestonia coalita e Rhabdadenia pohlii. Concluiu-se que os gêneros puderam ser separados utilizando-se as características polínicas e, dentro do gênero, as espécies estudadas apresentaram heterogeneidade polínica.
\end{abstract}

Palavras-chave: palinologia, Apocynaceae, Restinga de Carapebus, Rio de Janeiro

ABSTRACT - (Palynotaxonomy of the species of the Apocynaceae occur on the "restinga" of the Carapebus, Carapebus, Rio de Janeiro State, Brazil). Eleven species of Apocynaceae belonging to seven genera were palynologically studied in this work. The species occur in the "restinga" of Carapebus, located on the north coast of Rio de Janeiro State. The species were as followed: Aspidosperma parvifolium A. DC.; Forsteronia leptocarpa (Hook. \& Arns.) A. DC.; Himatanthus lancifolius (Müll. Arg.) Woodson; Mandevilla fragrans (Stadelm.) Woodson; Mandevilla sp.; M. moricandiana (A. DC.) Woodson; M. tenuifolia (J.C. Mikan) Woodson; Prestonia coalita (Vell.) Woodson; Rhabdadenia pohlii Müll. Arg.; Tabernaemontana flavicans Willd. ex Roem. \& Schult.; T. laeta Mart. The pollen grains were treated by the lactical acetolysis method, measured, described and illustrated by light microscopy and scanning electronic microscopy. The results obtained showed that two large groups can be identified: colporate pollen grains - Aspidosperma parvifolium (5-6-colporate, psilate exine, rugulate only apocolpus), Himatanthus lancifolius (3-colporate, reticulate exine), Tabernaemontana flavicans (4-colporate, endocingulate endoaperture) and T. laeta (3-4-colporate, rugulate exine); porate pollen grains - Forsteronia leptocarpa, the four species of Mandevilla, Prestonia coalita, Rhabdadenia pohlii. It was concluded that the genera could be separated by pollinical characters and within genera their species studied are heterogeneous palynologically.

Key words: palynology, Apocynaceae, “restinga” of Carapebus, Rio de Janeiro

\section{Introdução}

A família Apocynaceae compreende cerca de 300 gêneros e 2.000 espécies tropicais e subtropicais. No Brasil ocorrem cerca de 376 espécies subordinadas a 41 gêneros habitando diversas formações (Barroso et al. 1986). Esta família é bem representada na flora brasileira e, particularmente, no Rio de Janeiro; segundo levantamento realizado por Novaes \& Rapoporte (1996), são encontradas cerca de 80 espécies. As Apocynaceae têm como características marcantes a presença de látex nos órgãos vegetativos e reprodutivos e flores com prefloração contorta (Cronquist 1988).

O interesse pela palinologia de espécies de Apocynaceae ainda está incipiente, podendo-se citar Marques \& Melhem (1966) que descreveram 10 espécies de Apocynaceae encontradas no cerrado e, dentre elas, Aspidosperma tomentosum Mart., Himatanthus obovatus (Müll. Arg.) Woodson e Mandevilla illustris (Vell.) Woodson; Van Campo et al. (1979), que estudaram a palinotaxonomia de espécies de Tabernaemontana L. sensu lato enfatizando a ornamentação da parede; Nilsson (1986) que analisou os grãos de pólen de 17 gêneros com a

\footnotetext{
1 Parte da Dissertação de Mestrado do primeiro Autor

2 Departamento de Botânica, Museu Nacional/UFRJ, Quinta da Boa Vista, São Cristóvão, CEP 20940-040, Rio de Janeiro, RJ, Brasil

3 Autor para correspondência: esteves@plugue.com.br
} 
finalidade de oferecer visão geral da variabilidade morfológica polínica e, assim, poder avaliar a sua importância para a taxonomia; Nilsson (1990) que estudou a taxonomia e evolução à luz da morfologia polínica com base em 26 espécies de Apocynaceae (duas espécies de Tabernaemontana); Nilsson et al. (1993) que descreveram os grãos de pólen de espécies de Apocynaceae e de Periplocaceae procurando reconhecer as relações de parentesco entre as duas famílias. Dentre estes autores, apenas Marques \& Melhem (1966) e Van Campo et al. (1979) estudaram a palinologia de espécies brasileiras.

O presente estudo visa a caracterização polínica das espécies de Apocynaceae com o objetivo de auxiliar a taxonomia da família, oferecer subsídios às áreas afins, bem como contribuir para a formação do catálogo polínico da flora das restingas do Estado do Rio de Janeiro.

\section{Material e métodos}

O material botânico utilizado foi obtido de flores ou botões florais retirados de exsicatas depositadas no Herbário Alberto Castellanos (GUA), no Herbarium Bradeanum (HB), no Herbário do Museu Nacional do Rio de Janeiro (R), no Herbário do Jardim Botânico do Rio de Janeiro (RB), no Herbário da Universidade Federal do Rio de Janeiro (RFA), no Herbário Maria Eneyda P.K. Fidalgo, Instituto de Botânica de São Paulo (SP), no Herbário do Departamento de Botânica, Instituto de Biociências, Universidade de São Paulo (SPF) e no Herbário do Departamento de Botânica, Instituto de Biologia, Universidade Estadual de Campinas (UEC).

Para cada táxon, sempre que possível, procurou-se estudar três espécimes, sendo um deles escolhido como padrão, indicado no material examinado por um asterisco $(*)$, para as mensurações, descrições e ilustrações polínicas.

O material examinado foi: Aspidosperma parvifolium A. DC. - BRASIL. Minas Gerais: Lima Duarte, 29/XI/1994, V.C. de Almeida 33 (GUA); Rio Preto, 2/X/1959, M. Emmerich 213 (*R); Rio de Janeiro: Nova Friburgo, 18/XI/1891, s.col. (R12076); Rio Grande do Sul: Bento Gonçalves, 7/X/1971, EM. Santos 2652 (R). Forsteronia leptocarpa (Hook. \& Arns.) A. DC. - Espírito Santo: Bananal, X/1924, C. Vianna Freire s.n. (*R24181); Villa Nova, s.col., s.n. (R126752); Rio de Janeiro: Itaipuaçu, 28/XII/1988, A. Souza 2515 (R); Itaipuaçu, 1/I/1990, A. Souza 2861 (R). Himatanthus lancifolius (Müll.
Arg.) Woodson - Rio de Janeiro: Macaé, 27/XI/1985, D. Araújo 7085 (*GUA); Rio de Janeiro: Alto da Boa Vista, 2/III/1989, S.R. Sodré 138 (GUA); Ipanema, 29/II/1940, J.G. Kuhlmam 6013 (GUA); São José, IV/1979, P. Occhnión 8921 (RFA). Mandevilla fragrans (Stadelm.) Woodson - Rio de Janeiro: Carapebus, Restinga de Carapebus, 28/II/1996, J.G. da Silva 3064 (*R); Restinga de Carapebus, 28/XI/1996, A.S. de Oliveira 3796 (R); Magé, I/1953, J. Vidal 5844 (R); São Paulo: Bananal, 1/II/1883, M. Palma 1885 (R). Mandevilla sp. - Rio de Janeiro: Carapebus, 10/XI/1994, J. Fontella 3196 $(* \mathrm{R})$; Rio de Janeiro, restinga de Jacarepaguá, Pedra de Itaúna, 11/V/1973, W.N. Vidal 281 (UEC); Rio de Janeiro, 10/V/1969, D. Sucre 5005 (SP); restinga de Jacarepaguá, 25/VI/1993, D. Sucre s.n. (UEC44962); Rio de Janeiro. Mandevilla moricandiana (A. DC.) Woodson - Rio de Janeiro: Carapebus, 27/VI/1996, V.L.C. Martins 320 (*R); Carapebus, Restinga de Carapebus, 29/V/1997, M.G. Santos 910 (R); Carapebus, 16/III/1995, A. Souza 3732 (R); Macaé, 10/II/1981, D. Araújo 4276 (GUA). Mandevilla tenuifolia (J.C. Mikan) Woodson - Bahia: Caeté, Serra da Piedade, s.d., Mello Barreto s.n. (*R41328); Minas Gerais: Serra do Caparaó, 10/VII/1997, L.B. Santos s.n. (R111184); Serra do Cipó, X/1954, s.col. (R165043); Serra do Cipó, XI-XII/1954, s.col. (R165046). Prestonia coalita (Vell.) Woodson - Rio de Janeiro: Carapebus, Restinga de Carapebus, s.d., V. Capello 29 (R); Rio de Janeiro, restinga da Marambaia, 30/I/1992, D. Araújo 9555 (*R); São Paulo: Iguape, s.d., A.P. Brade 9129 (R22033); São Paulo, Parque do Estado, 28/I/1932, F.C. Hoehne s.n. (R112810). Rhabdadenia pohlii Müll. Arg. - Rio de Janeiro: Cachoeira de Macacu, 4/X/1959, G.F.J. Pabst 4888 (HB); Carapebus, 7/XII/1994, J. Fontella s.n. (*R187251); Itaipuaçu, 21/I/1987, A. Souza 1563 (R162366); São Paulo: Juquiá, 15/10/1961, G. Pabst 5817 (HB 21691). Tabernaemontana flavicans Willd. ex Roem. \& Schult. - Bahia: Porto Seguro, 19/X/1969, J.A. de Jesus 471 (*RB); Pará: Rio Tocantins, 1/XI/1915, A. Ducke s.n. (RB21781); Rio Trombetas, s.d., A. Ducke s.n. (RB21795); Pernambuco: Rio Formoso, 23/IX/1954, J.I.A. Falcão 1203 (RB89114). Tabernaemontana laeta Mart. - Rio de Janeiro: Mangaratiba, Vale do Rio do Saco, 18/XI/1986, J.P.P. Carauta 5396 (*GUA); Rio de Janeiro, Corcovado, 2/XI/1864, s.col. (R12098); Estrada das Furnas, 21/II/1966, J.P. Lanna 1236 (GUA); Reserva Biológica de Jacarepaguá, 18/IV/1964, A. Castellanos s.n. (GUA06955). 
Mandevilla sp., é, possivelmente, uma espécie nova (M. Sales, dados não publicados). F. Moreira (dados não publicados) reconheceu a existência dessa nova espécie e, por esse motivo, ela é aqui estudada palinologicamente.

Para a análise sob microscopia de luz foi utilizado o método de acetólise láctica a 60\% (Raynal \& Raynal 1971) por serem os grãos de pólen, na maioria, muito frágeis. Os grãos de pólen foram medidos e fotomicrografados até três dias após sua preparação, visando evitar qualquer deformação (Wanderley \& Melhem 1991). Para a obtenção das elétromicrografias, retirou-se duas a três anteras utilizando-se pinças e estiletes devidamente flambados, posteriormente macerou-se as anteras, liberando os grãos de pólen (não acetolisados) sobre suporte previamente recoberto por fita adesiva de carbono dupla face. O material sobre o suporte foi metalizado com ouro por três minutos. Levou-se o suporte para a observação ao microscópio eletrônico de varredura (MEV). Do material padrão foram medidos, aleatoriamente, 25 grãos de pólen distribuídos num mínimo de três lâminas com a finalidade de homogeneizar a amostra, conforme SalgadoLabouriau (1973). Foram medidos em vista equatorial, o diâmetro equatorial (DE) e o diâmetro polar (DP); em vista polar, foram medidos o lado da apocolpo (LA) e o diâmetro equatorial (DEVP).

Foram realizados os tratamentos estatísticos calculando-se a média aritmética $(\overline{\mathrm{x}})$, o desvio padrão da amostra (s), o desvio padrão da média $\left(\mathrm{S}_{\overline{\mathrm{x}}}\right)$ o coeficiente de variabilidade (CV\%), o intervalo de confiança a 95\% (IC 95\%) e a faixa de variação. Para os demais caracteres, como as aberturas e as camadas da exina, foi calculada a média aritmética de 10 medidas, o mesmo ocorrendo para as medidas dos diâmetros dos grãos de pólen do material de comparação. A terminologia adotada foi a de Barth \& Melhem (1988) e a de Punt et al. (1999); a denominação da área polar e do tamanho da abertura estão de acordo com a classificação estabelecida por Faegri \& Iversen (1964) para o índice da área polar.

\section{Resultados}

\section{Aspidosperma parvifolium A. DC.}

\section{Fig. 1-5.}

Grãos de pólen médios, isopolares, suboblatos, âmbito circular, área polar pequena (Tab. 1, 2), 5-6-colporados (Fig. 1, 2), sexina psilada no mesocolpo, rugulada, com perfurações nos pólos. Os colpos são longos, largos (Tab. 3), recobertos por membrana ornamentada e contornados por margem muito espessa, proeminente (Fig. 5), que dificulta a observação da abertura, endoabertura lalongada (Fig. 3). A exina é psilada em quase toda a superfície e rugulada apenas na região do apocolpo (Fig. 2, 4), a sexina é quase tão espessa quanto à nexina.

Nos três materiais usados como comparação dos resultados (Tab. 4) os valores encontrados para os diâmetros polar e equatorial ficam fora dos limites do intervalo de confiança e da faixa de variação, com exceção do exemplar R145067.

\section{Forsteronia leptocarpa (Hook. \& Arns.) A. DC.}

Fig. 6-11.

Grãos de pólen médios, isopolares, oblatoesferoidais ou esferoidais, âmbito circular, área polar muito grande (Tab. 1, 2), 3-4-zonoporados (Fig. 6), sexina escabrada no mesocolpo, rugulada, com rúgulas conspícuas e perfurações próximas das aberturas. Os poros apresentam ânulus espesso, psilado (Fig. 7, 9). A exina é escabrada quando observada sob ML (Fig. 7); sob MEV pode-se comprovar que a exina é psilada no mesocolpo (Fig. 8) e rugulada com perfurações nas proximidades do poro (Fig. 9, 11). A sexina é tão espessa quanto à nexina.

Os espécimes usados como comparação dos resultados (Tab. 4) apresentam variação na forma (R178068) e os valores dos diâmetros polar e equatorial ficam dentro da faixa de variação e/ou dentro do intervalo de confiança.

\section{Himatanthus lancifolius (Müll. Arg.) Woodson}

Fig. 12-17.

Grãos de pólen médios, isopolares, suboblatos a prolato-esferoidais, âmbito subtriangular, área polar pequena (Tab. 1, 2), 3-colporados, (Fig. 12, 13), sexina heterorreticulada. Os colpos são grandes (Fig. 16, 17) ficando o apocolpo limitado a uma região muito pequena (Fig. 12, 13), endoabertura lalongada, ampla. A exina é heterorreticulada (Fig. 14, 15), retículos de lúmens pequenos; a sexina é mais espessa do que a nexina.

Os espécimes usados para comparação dos resultados (Tab. 4) apresentam variação na forma e os valores encontrados nos diâmetros polar e equatorial ficam fora dos limites do intervalo de confiança e da faixa de variação.

\section{Mandevilla sp.}

Fig. 18-39.

Espécies estudadas: M. fragrans (Fig. 18-23), Mandevilla sp. (Fig. 24-29), M. moricandiana 
(Fig. 30-34), M. tenuifolia (Fig. 35-39).

Grãos de pólen médios ou grandes (em Mandevilla sp.), isopolares, oblato-esferoidais, âmbito circular, área polar grande (Tab. 1, 2), 4-zonoporados (M. fragrans e $M$. tenuifolia) ou 4-5-zonoporados (Mandevilla sp. e M. moricandiana), sexina psilada com perfurações, escabrada ou rugulada com perfurações, rúgulas conspícuas ou não. Os poros possuem ânulus psilado, espesso, que projeta a abertura (Fig. 26, 27, 33). Os maiores poros são encontrados em Mandevilla sp. (Tab. 3). A sexina apresenta-se escabrada ( $M$. fragrans) ou rugulada quando observada sob ML (Fig. 19, 25, 36) porém, sob MEV pode-se comprovar que a sexina é formada por rúgulas inconspícuas, com perfurações em $M$. fragrans e M. moricandiana (Fig. 20, 34); a sexina é psilada, com perfurações em M. tenuifolia (Fig. 37, 39) e, em Mandevilla sp., a sexina apresenta rúgulas conspícuas com perfurações (Fig. 29). A sexina é quase tão espessa quanto à nexina em $M$. fragrans e Mandevilla sp.; a sexina é tão espessa quanto à nexina, em M. moricandiana e M. tenuifolia (Tab. 3).
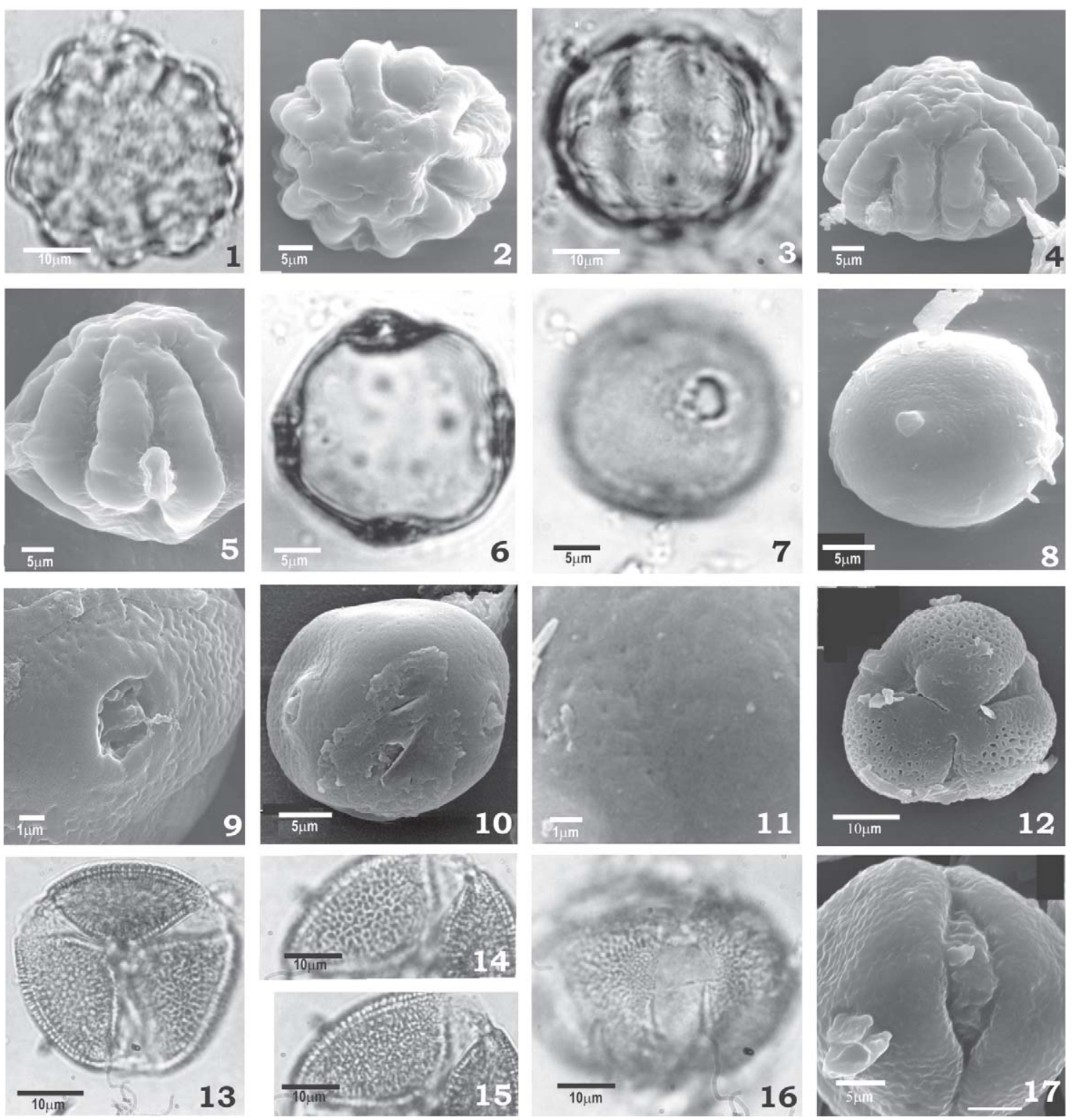

Figuras 1-5. Grãos de pólen de Aspidosperma parvifolium A. DC. Vista polar: 1. Âmbito. 2. Âmbito e apocolpo, superfície. Vista equatorial: 3. Abertura. 4. Apocolpo e abertura. 5. Abertura, superfície. 6-11. Forsteronia leptocarpa (Hook. \& Arns.). Vista polar: 6. Corte óptico. Vista equatorial: 7-8. Abertura. 9. Superfície e abertura. 10. Mesoporo. 11. Superfície com perfurações. 12-17. Himatanthus lancifolius (Müll. Arg.). Vista polar: 12. Superfície. 13. Corte óptico. 14-15. Análise de L.O. Vista equatorial: 16, 17. Abertura. 
Tabela 1. Medidas $(\mu \mathrm{m})$ dos grãos de pólen em vista equatorial, de espécies de Apocynaceae (n = 25).

\begin{tabular}{|c|c|c|c|c|c|c|c|c|c|c|c|}
\hline \multirow[b]{2}{*}{ Espécies } & \multicolumn{5}{|c|}{ Diâmetro polar } & \multicolumn{5}{|c|}{ Diâmetro equatorial } & \multirow[b]{2}{*}{$\mathrm{P} / \mathrm{E}$} \\
\hline & $\begin{array}{l}\text { Faixa de } \\
\text { variação }\end{array}$ & $\bar{x} \pm S_{\bar{x}}$ & $\mathrm{~s}$ & $\mathrm{CV} \%$ & IC 95\% & $\begin{array}{l}\text { Faixa de } \\
\text { variação }\end{array}$ & $\bar{x}+s_{\bar{x}}$ & $\mathrm{~s}$ & CV \% & IC 95\% & \\
\hline Aspidosperma parvifolium & $32,5-35,0$ & $34,4 \pm 0,2$ & 1,1 & 3,1 & $34,0-34,8$ & $37,5-40,0$ & $39,4 \pm 0,2$ & 1,1 & 2,7 & $38,9-39,9$ & 0,87 \\
\hline Forsteronia leptocarpa & $22,5-27,5$ & $25,1 \pm 0,3$ & 1,3 & 5,2 & $24,5-25,6$ & $22,5-27,7$ & $25,4 \pm 0,2$ & 1,2 & 4,6 & $24,9-25,9$ & 0,99 \\
\hline Himatanthus lancifolius & $25,0-27,5$ & $26,2 \pm 0,2$ & 1,2 & 4,6 & $25,8-26,6$ & $30,0-32,5$ & $32,0 \pm 0,2$ & 1,1 & 3,4 & $31,6-32,4$ & 0,82 \\
\hline Mandevilla fragrans & $30,0-36,2$ & $33,5 \pm 0,3$ & 1,7 & 5,2 & $32,8-34,2$ & $32,5-37,5$ & $35,6 \pm 0,3$ & 1,8 & 5,1 & $34,8-36,3$ & 0,94 \\
\hline Mandevilla sp. & $70,0-77,5$ & $73,6 \pm 0,4$ & 2,3 & 3,1 & $72,7-74,6$ & $72,5-80,0$ & $76,3 \pm 0,5$ & 2,5 & 3,2 & $75,3-77,3$ & 0,96 \\
\hline M. moricandiana & $35,0-40,0$ & $38,4 \pm 0,3$ & 1,4 & 3,6 & $37,8-38,9$ & $37,5-42,5$ & $41,5 \pm 0,3$ & 1,5 & 3,5 & $41,0-42,1$ & 0,92 \\
\hline M. tenuifolia & $32,5-37,5$ & $35,0 \pm 0,2$ & 1,2 & 3,6 & $34,5-35,5$ & $37,5-42,5$ & $38,0 \pm 0,3$ & 1,5 & 3,8 & $37,4-38,6$ & 0,92 \\
\hline Prestonia coalita & $42,5-45,0$ & $44,0 \pm 0,2$ & 1,2 & 2,8 & $43,5-44,5$ & $45,0-47,5$ & $45,8 \pm 0,2$ & 1,2 & 2,6 & $45,3-46,3$ & 0,96 \\
\hline Rhabdadenia pohlii & $56,2-61,2$ & $58,2 \pm 0,3$ & 1,5 & 2,7 & $57,6-58,9$ & $60,0-62,5$ & $60,8 \pm 0,2$ & 1,0 & 1,5 & $60,4-61,2$ & 0,95 \\
\hline Tabernaemontana flavicans & $35,0-40,0$ & $38,2 \pm 0,3$ & 1,3 & 3,4 & $37,6-38,7$ & $45,0-47,5$ & $45,9 \pm 0,2$ & 1,2 & 2,6 & $45,4-46,4$ & 0,83 \\
\hline T. laeta & $25,0-27,5$ & $25,6 \pm 0,2$ & 1,1 & 4,1 & $25,1-26,0$ & $30,0-32,5$ & $30,2 \pm 0,1$ & 0,7 & 2,2 & $30,0-30,5$ & 0,84 \\
\hline
\end{tabular}

$\overline{\mathrm{X}}$ - média aritmética; s s - desvio padrão da média; s - desvio padrão da amostra; CV - intervalo de confiança a 95\%; IC - coeficiente de variabilidade; P/E - relação entre o diâmetro polar e o diâmetro equatorial.

Os resultados encontrados no estudo do material de comparação (Tab. 4) mostra que na maioria dos espécimes, a forma é constante e semelhante a do material padrão. Os valores obtidos dos diâmetros polar e equatorial ficam dentro dos limites da faixa de variação quando comparados com os do material padrão, exceto em M. moricandiana (R18946, R192189) e M. tenuifolia (R165046). Mandevilla sp. é a espécie que apresenta grãos de pólen mais frágeis, que deformam com o processo de preparação.

\section{Prestonia coalita (Vell.) Woodson}

Fig. 40-43.

Grãos de pólen médios, isopolares, oblatoesferoidais, âmbito circular, área polar grande (Tab. 1,
2), 3-4-zonoporados (Fig. 43), sexina rugulada. Os poros apresentam ânulus espesso, psilado, que projeta a abertura (Fig. 43). A sexina é formada por rúgulas conspícuas (Fig. 41). Sexina tão espessa quanto à nexina (Tab. 3).

Os materiais de comparação (Tab. 4) apresentam forma oblato-esferoidal e os valores encontrados para os diâmetros polar e equatorial ficam dentro dos limites do intervalo de confiança e/ou da faixa de variação.

Rhabdadenia pohlii Müll. Arg.

Fig. 44-48.

Grãos de pólen grandes, isopolares, oblatoesferoidais ou prolato-esferoidais, área polar grande,

Tabela 2. Medidas ( $\mu \mathrm{m})$ dos grãos de pólen em vista polar: diâmetro equatorial (DEVP); lado do apocolpo (LA) e índice da área polar (IAP) de espécies de Apocynaceae $(\mathrm{n}=10)$.

\begin{tabular}{|c|c|c|c|c|c|c|}
\hline \multirow[b]{2}{*}{ Espécies } & \multicolumn{2}{|c|}{ Diâmetro equatorial } & \multicolumn{2}{|l|}{ LA } & \multirow[t]{2}{*}{ IAP } & \multirow{2}{*}{$\begin{array}{l}\text { Área polar } \\
\text { LA/DEVP }\end{array}$} \\
\hline & Faixa de variação & $\bar{x}$ & Faixa de variação & $\bar{x}$ & & \\
\hline Aspidosperma parvifolium & $35,0-37,5$ & 37,1 & $20,0-22,5$ & 22,2 & 0,60 & grande \\
\hline Forsteronia leptocarpa & $22,5-27,5$ & 24,7 & $17,5-20,0$ & 19,2 & 0,78 & muito grande \\
\hline Himatanthus lancifolius & $30,0-32,5$ & 30,7 & $10,0-15,0$ & 13,0 & 0,42 & pequena \\
\hline Mandevilla fragrans & $32,5-35,0$ & 33,9 & $22,5-25,0$ & 24,0 & 0,71 & grande \\
\hline Mandevilla sp. & $70,0-77,5$ & 74,0 & $50,0-52,5$ & 51,0 & 0,69 & grande \\
\hline M. moricandiana & $40,0-45,0$ & 42,3 & $27,5-30,0$ & 29,5 & 0,70 & grande \\
\hline M. tenuifolia & $35,0-40,0$ & 38,3 & $25,0-27,5$ & 26,8 & 0,70 & grande \\
\hline Prestonia coalita & $42,5-47,5$ & 44,9 & $30,0-32,5$ & 31,4 & 0,70 & grande \\
\hline Rhabdadenia pohlii & $60,0-62,5$ & 62,2 & $40,0-45,0$ & 42,4 & 0,68 & grande \\
\hline Tabernaemontana flavicans & $35,0-37,5$ & 36,2 & $25,0-27,5$ & 25,4 & 0,70 & grande \\
\hline T. laeta & $27,5-32,5$ & 30,0 & $22,5-25,0$ & 24,5 & 0,82 & muito grande \\
\hline
\end{tabular}


Tabela 3. Medidas $(\mu \mathrm{m})$ das aberturas e da exina dos grãos de pólen de espécies de Apocynaceae $(\mathrm{n}=10)$.

\begin{tabular}{|c|c|c|c|c|c|c|c|c|c|c|c|}
\hline \multirow[t]{2}{*}{ Espécies } & \multicolumn{2}{|c|}{ Colpo } & \multicolumn{3}{|c|}{ Endoabertura } & \multicolumn{3}{|c|}{ Poro } & \multicolumn{3}{|c|}{ Espessura da exina } \\
\hline & compr. & larg. & compr. & larg. & margem & D1 & D2 & ânulus & exina & sexina & nexina \\
\hline Aspidosperma parvifolium & 27,1 & 5,0 & 7,8 & 5,0 & 5,3 & - & - & - & 1,9 & 1,0 & 0,9 \\
\hline Forsteronia leptocarpa & - & - & - & - & - & 2,9 & 2,9 & 1,0 & 1,0 & 0,5 & 0,5 \\
\hline Himatanthus lancifolius & 19,9 & 4,6 & 5,5 & 6,9 & 1,5 & - & - & - & 2,7 & 1,7 & 1,0 \\
\hline Mandevilla fragrans & - & - & - & - & - & 7,3 & 7,2 & 0,7 & 1,7 & 0,9 & 0,8 \\
\hline Mandevilla sp. & - & - & - & - & - & 12,0 & 11,8 & 2,7 & 1,2 & 0,7 & 0,5 \\
\hline M. moricandiana & - & - & - & - & - & 5,7 & 6,0 & 1,0 & 1,0 & 0,5 & 0,5 \\
\hline M. tenuifolia & - & - & - & - & - & 4,8 & 4,8 & 1,6 & 1,0 & 0,5 & 0,5 \\
\hline Prestonia coalita & - & - & - & - & - & 5,4 & 5,5 & 2,0 & 1,0 & 0,5 & 0,5 \\
\hline Rhabdadenia pohlii & - & - & - & - & - & 11,3 & 10,7 & 0,5 & 2,1 & 1,1 & 1,0 \\
\hline Tabernaemontana flavicans & 12,7 & 2,1 & 4,1 & - & - & - & - & - & 1,5 & 0,6 & 0,9 \\
\hline T. laeta & 13,3 & 3,4 & 4,7 & 6,8 & 1,2 & - & - & - & 2,0 & 1,0 & 1,0 \\
\hline
\end{tabular}

compr. - comprimento; larg. - largura; D1 - Diâmetro 1; D2 - Diâmetro 2.

Tabela 4. Medidas ( $\mu \mathrm{m})$ dos grãos de pólen em vista equatorial dos materiais de comparação (n=10).

\begin{tabular}{|c|c|c|c|c|}
\hline Espécimes & Diâmetro polar & Diâmetro equatorial & $\mathrm{P} / \mathrm{E}$ & Forma \\
\hline \multicolumn{5}{|c|}{ Aspidosperma parvifolium } \\
\hline GUA45158 & 32,2 & 38,7 & 0,83 & suboblata \\
\hline R12076 & 35,7 & 41,5 & 0,86 & suboblata \\
\hline R145067 & 32,7 & 37,5 & 0,87 & suboblata \\
\hline \multicolumn{5}{|c|}{ Forsteronia leptocarpa } \\
\hline R21574 & 25,0 & 26,0 & 0,96 & oblato-esferoidal \\
\hline R178068 & 26,5 & 26,5 & 1,0 & esferoidal \\
\hline \multicolumn{5}{|c|}{ Himatanthus lancifolius } \\
\hline GUA29816 & 28,1 & 25,6 & 1,1 & prolato-esferoidal \\
\hline GUA34761 & 31,2 & 26,0 & 1,2 & prolato-esferoidal \\
\hline GUA20510 & 28,4 & 25,6 & 1,1 & prolato-esferoidal \\
\hline \multicolumn{5}{|c|}{ Mandevilla fragrans } \\
\hline R190407 & 34,2 & 34,5 & 0,99 & oblato-esferoidal \\
\hline R165095 & 32,5 & 33,7 & 0,96 & oblato-esferoidal \\
\hline R165156 & 32,5 & 32,7 & 0,99 & oblato-esferoidal \\
\hline \multicolumn{5}{|l|}{ Mandevilla sp. } \\
\hline SP177225 & 75,5 & 79,7 & 0,95 & oblato-esferoidal \\
\hline UEC44947 & 75,2 & 79,0 & 0,95 & oblato-esferoidal \\
\hline UEC44962 & 74,7 & 78,7 & 0,95 & oblato-esferoidal \\
\hline \multicolumn{5}{|c|}{ M. moricandiana } \\
\hline R18946 & 44,7 & 47,2 & 0,95 & oblato-esferoidal \\
\hline R187253 & 37,8 & 41,2 & 0,92 & oblato-esferoidal \\
\hline R192189 & 42,2 & 45,5 & 0,93 & oblato-esferoidal \\
\hline \multicolumn{5}{|l|}{ M. tenuifolia } \\
\hline R111184 & 37,0 & 39,2 & 0,94 & oblato-esferoidal \\
\hline R165043 & 35,7 & 38,0 & 0,94 & oblato-esferoidal \\
\hline R165046 & 40,5 & 42,2 & 0,96 & oblato-esferoidal \\
\hline \multicolumn{5}{|c|}{ Prestonia coalita } \\
\hline R22033 & 43,5 & 44,0 & 0,99 & oblato-esferoidal \\
\hline R112810 & 44,2 & 45,7 & 0,97 & oblato-esferoidal \\
\hline R192081 & 44,7 & 46,2 & 0,97 & oblato-esferoidal \\
\hline \multicolumn{5}{|c|}{ Rhabdadenia pohlii } \\
\hline R18022 & 60,5 & 58,6 & 1,03 & prolato-esferoidal \\
\hline R21691 & 58,2 & 61,0 & 0,95 & oblato-esferoidal \\
\hline R162366 & 59,7 & 61,7 & 0,97 & oblato-esferoidal \\
\hline
\end{tabular}


Tabela 4 (continuação)

\begin{tabular}{|c|c|c|c|c|}
\hline Espécimes & $\underset{\bar{x}}{\text { Diâmetro polar }}$ & $\underset{\bar{x}}{\text { Diâmetro equatorial }}$ & $\mathrm{P} / \mathrm{E}$ & Forma \\
\hline \multicolumn{5}{|c|}{ Tabernaemontana flavicans } \\
\hline RB89114 & 36,0 & 46,0 & 0,98 & oblato-esferoidal \\
\hline RB21795 & 36,7 & 39,7 & 0,92 & oblato-esferoidal \\
\hline RB44384 & 37,2 & 44,1 & 0,84 & suboblata \\
\hline \multicolumn{5}{|l|}{ T. laeta } \\
\hline GUA1625 & 25,5 & 30,2 & 0,84 & suboblata \\
\hline GUA6955 & 25,7 & 30,2 & 0,85 & suboblata \\
\hline GUA12098 & 26,0 & 30,7 & 0,85 & suboblata \\
\hline
\end{tabular}

X - média aritmética; P/E - relação entre o diâmetro polar e o diâmetro equatorial.

âmbito circular, 3-4-zonoporados (Fig. 47), sexina rugulada. Os poros possuem ânulus espesso, psilado (Fig. 46). A exina é formada por rúgulas conspícuas (Fig. 48); a sexina é tão espessa quanto à nexina (Tab. 3).

Os materiais de comparação (Tab. 4) apresentam grãos de pólen com a mesma forma do material padrão, exceto o espécime R18022 que possui forma prolatoesferoidal. Os valores dos diâmetros polar e equatorial dos grãos de pólen dos espécimes de comparação ficam dentro dos limites do intervalo de confiança e/ou da faixa de variação, quando comparados com o material padrão.

\section{Tabernaemontana L.}

Fig. 49-61.

Espécies estudadas: T. flavicans Willd. ex Roem. \& Shult. (Fig. 49-56), T. laeta Mart. (Fig. 57-61).

Grãos de pólen médios, isopolares, suboblatos (T. laeta) ou oblato-esferoidais, área polar grande (T. laeta) ou muito grande em T. flavicans (Tab. 1, 2), âmbito circular (T. flavicans) ou subcircular, 3-4-colporados em T. laeta (Fig. 57), 4-colporados, endocingulados em $T$. flavicans (Fig. 49, 52), sexina rugulada. Os colpos são curtos em T. laeta ou muito curtos em T. flavicans (Tab. 3), a endoabertura é lalongada em T. laeta (Fig. 59) e endocingulada em T. flavicans (Fig. 52, 53). A exina é rugulada, com perfurações esparsas, as rúgulas são mais conspícuas em T. flavicans (Fig. 51, 57). A sexina é tão espessa quanto à nexina ou aproximadamente da mesma espessura.

Dentre os materiais de comparação (Tab. 4) das espécies de Tabernaemontana estudadas, os espécimes de $T$. flavicans apresentam grãos de pólen com forma diferente daquela encontrada no material padrão, exceto o espécime RB44384 cujos grãos de pólen possuem forma suboblata; em T. laeta, os espécimes de comparação apresentam a mesma forma do material padrão. Os valores dos diâmetros polar e equatorial dos grãos de pólen dos espécimes de comparação das duas espécies de Tabernaemontana ficam dentro dos limites do intervalo de confiança e/ou da faixa de variação, quando comparados com o material padrão, exceto os espécimes (RB21795 e RB44384) de T. flavicans que apresentam os valores do diâmetro equatorial fora dos limites tanto da faixa de variação quanto do intervalo de confiança.

Chave polínica para separação das espécies de Apocynaceae estudadas

1. Grãos de pólen colporados

2. Grãos de pólen 5-6 colporados, com margem muito espessa, proeminente Aspidosperma parvifolium

2. Grãos de pólen 3-colporados ou 3-4-colporados, sem margem espessa ou, se espessa, não proeminente

3. Grãos de pólen 3-colporados, exina reticulada

Himatanthus lancifolius

3. Grãos de pólen 3-4 ou 4-colporados, exina rugulada

4. Grãos de pólen 3-4-colporados, endoabertura lalongada não endocingulada

Tabernaemontana laeta

4. Grãos de pólen 4-colporados, endoabertura endocingulada Tabernaemontana flavicans 

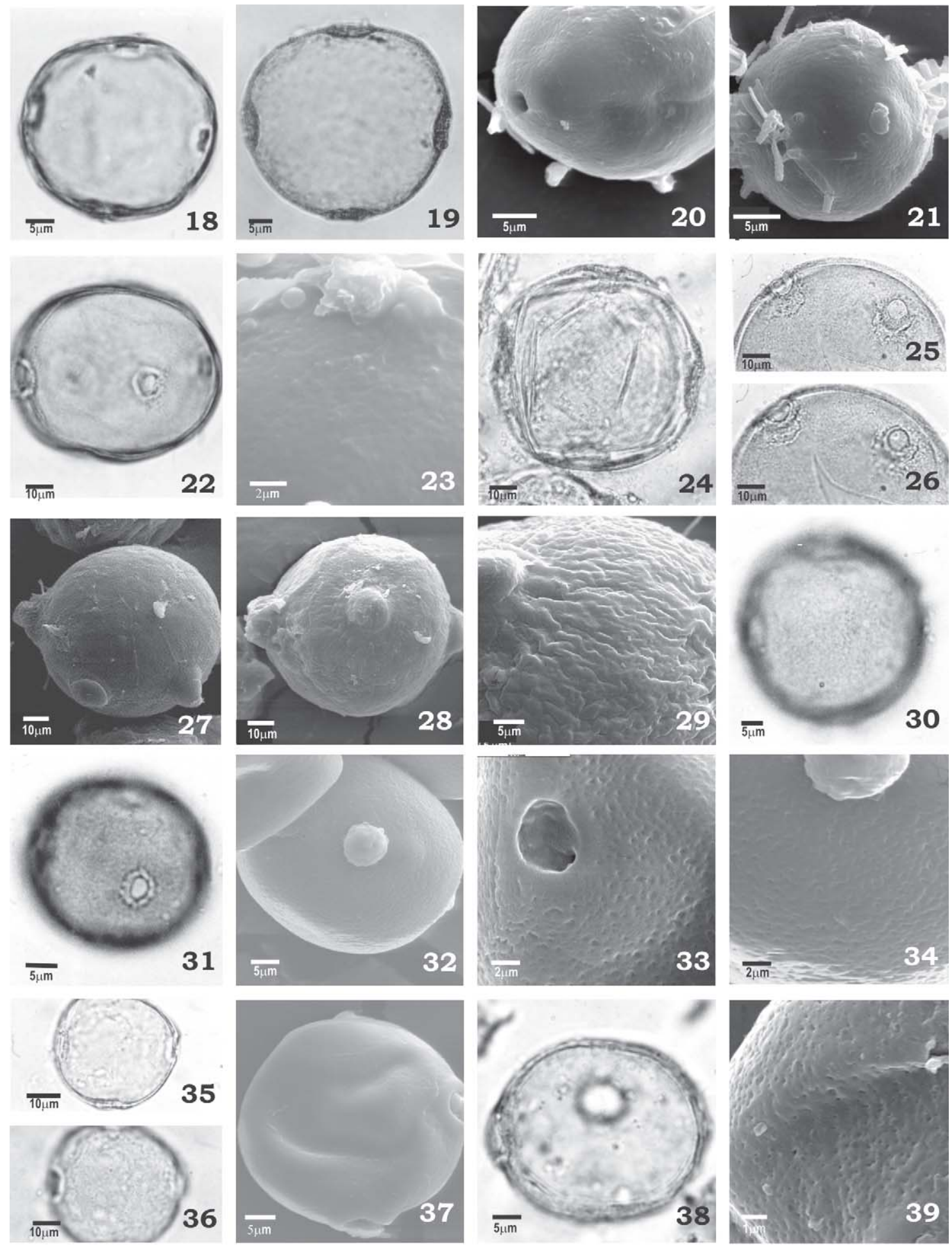

Figuras 18-23. Grãos de pólen de Mandevilla fragrans (Stadelm.). Vista polar: 18. Corte óptico. 19. Superfície. Vista equatorial: 20. Superfície no mesoporo. 21-22. Abertura. 23. Superfície. 24-29. Mandevilla sp. Vista polar: 24. Corte óptico. 25-26. Análise de LO. 27. Superfície no mesoporo. Vista equatorial: 28. Abertura. 29 Superfície. 30-34. Mandevilla moricandiana (A. DC.). Vista polar: 30. Superfície. Vista equatorial: 31-32. Abertura. 33. Superfície próximo da abertura. 34. Superfície. 35-39. Mandevilla tenuifolia (J.C. Mikan) Woodson. Vista polar: 35. Corte óptico. 36. Superfície. 37. Superfície na região do apoporo. Vista equatorial: 38. Corte óptico. 39. Superfície. 

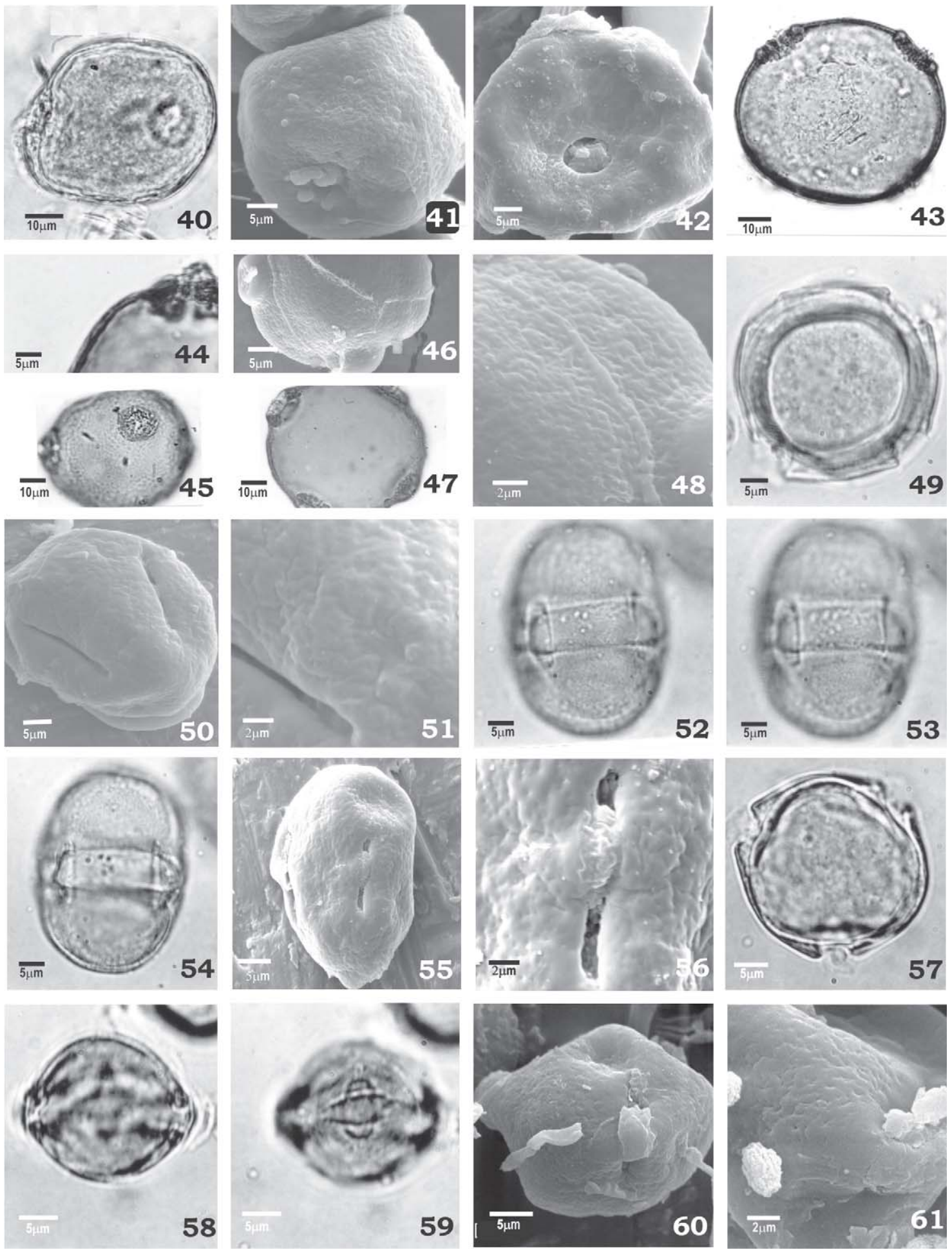

Figuras 40-44. Grãos de pólen de Prestonia coalita (Vell.) Woodson. Vista equatorial: 40. Âmbito. 41-42. Abertura e superfície. Vista polar: 43. Superfície. 44. Corte óptico e abertura. 45-48. Rhabdadenia pohlii Müll. Arg. Vista equatorial: 45. Superfície próximo da abertura. 46. Superfície. Vista polar: 47. Apoporo. 48. Superfície. 49-56. Tabernaemontana flavicans Willd. ex Roem. \& Schult. Vista polar: 49. Âmbito. 50-51. Superfície na região do apocolpo. Vista equatorial: 52-54. Análise de L.O. 55. Abertura. 56. Superfície e abertura. 57-61. Tabernaemontana laeta Mart. Vista polar: 57. Corte óptico. Vista equatorial: 58. Âmbito. 59-60. Abertura. 61. Superfície. 
1. Grãos de pólen porados

5. Grãos de pólen grandes (50-100 $\mu \mathrm{m})$

6. Grãos de pólen 4-5-zonoporados, poro ca. $12 \mu \mathrm{m}$, I.C. 95\%: 72-77 $\mu \mathrm{m}$ Mandevilla sp.

6. Grãos de pólen 3-4-zonoporados, poro ca. $11 \mu \mathrm{m}$, I.C. 95\%: 59-61 $\mu \mathrm{m}$ Rhabdadenia pohlii

5. Grãos de pólen médios (25-50 $\mu$ m)

7. Grãos de pólen 4-zonoporados ou 4-5-zonoporados

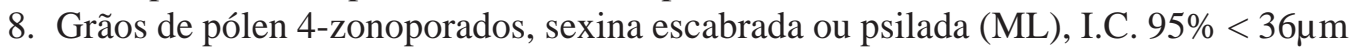

9. Sexina psilada, poro ca. $5 \mu \mathrm{m}$ Mandevilla tenuifolia

9. Sexina escabrada (ML) ou comrúgulas inconspícuas (MEV), poro ca.7,0 $\mu \mathrm{m}$

Mandevilla fragrans

8. Grãos de pólen 4-5-zonoporados, sexina com rúgulas inconspícuas, poro ca. $6 \mu \mathrm{m}$, I.C. $95 \%>38 \mu \mathrm{m}$ Mandevilla moricandiana

7. Grãos de pólen 3-4-zonoporados

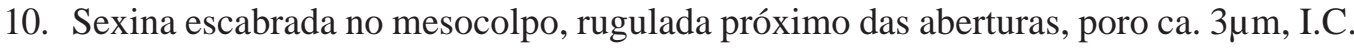
95\%: $24-26 \mu \mathrm{m}$ Forsteronia leptocarpa 10. Sexina rugulada em toda a superfície, poro ca. 5,5 $\mu$ m, I.C. 95\%: $43-46 \mu \mathrm{m}$........ Prestonia coalita

\section{Discussão}

As espécies de Apocynaceae analisadas no presente trabalho apresentaram diferenças morfológicas nos seus grãos de pólen. Os sete gêneros estudados puderam ser separados pelo tipo e número de aberturas (colporados e porados), pela ornamentação da exina e pelo tamanho dos grãos de pólen. Aspidosperma parvifolium caracterizou-se por ter grãos de pólen 5-6-colporados e exina psilada, rugulada apenas no apocolpo; Himatanthus lancifolius por apresentar 3-cólporos e exina reticulada; as espécies de Tabernaemontana apresentaram diferença na quantidade e no tipo de abertura: 3-4 cólporos, endoabertura lalongada em T. laeta e 4 cólporos, endoabertura endocingulada em T. flavicans. As espécies de Mandevilla, Forsteronia leptocarpa, Prestonia coalita e Rhabdadenia pohlii tiveram como característica semelhante, a abertura do tipo poro; no entanto, puderam ser separadas pelo tamanho: médio $(25-50 \mu \mathrm{m})$, na maioria das espécies e grande (50-100 $\mu \mathrm{m})$ em Mandevilla sp. e R. pohlii. A área polar foi pequena em Aspidosperma parvifolium e Himatanthus lancifolius, grande em todas as espécies de Mandevilla, Prestonia coalita, Rhabdadenia pohlii e Tabernaemontana laeta, área polar muito grande foi encontrada apenas em Forsteronia leptocarpa e Tabernaemontana flavicans. A ornamentação da exina também permitiu a identificação destas espécies, sendo rugulada, com rúgulas conspícuas em $P$. coalita, escabrada ou com rúgulas inconspícuas em $M$. fragrans, psilada em $M$. tenuifolia e escabrada no mesocolpo com rúgulas próximo das aberturas em F. leptocarpa.
Espécies de Aspidosperma foram analisadas, palinologicamente, por Marques \& Melhem (1966) e Nilsson (1986). As primeiras autoras examinaram A. tomentosum Mart. que foi caracterizada por possuir grãos de pólen prolato-esferoidais, 4-pseudocolpados, 4-colpados, colpos com margem espessa e exina provavelmente psilada. Nilsson (1986) estudou duas espécies diferentes de Aspidosperma considerando os grãos de pólen muito semelhantes aos de Geissospermum argenteum Woodson. Segundo esse autor os grãos de pólen das espécies possuíam 3-cólporos, a forma variou de quase esferoidal a subprolata, margem dos colpos com duas elevações que projetavam a região da endoabertura e a exina foi descrita como perforada. Aspidosperma parvifolium apresentou características polínicas diferentes das espécies estudadas por estes autores no que se refere à forma do grão de pólen, à ornamentação da parede e pela ausência de pseudocolpo.

Os grãos de pólen de Himatanthus obovatus (Müll. Arg.) Woodson e Mandevilla illustris (Vell.) Woodson foram analisados por Marques \& Melhem (1966) como tendo, respectivamente, forma oblatoesferoidal, 3-clinocolpado-3-colporados, exina reticulada ( $H$. obovatus) e suboblatos, 4-(5)-porados, exina reticulada ( $M$. illustris). Os grãos de pólen de $H$. lancifolius, espécie aqui estudada, apresentaram, de forma geral, as características semelhantes àquelas encontradas em $H$. obovatus diferindo na qualidade da abertura pois não foram encontrados clinopolpos. No presente estudo foram analisados os grãos de pólen de quatro espécies de Mandevilla que apresentaram exina com ornamentação psilada, escabrada ou rugulada porém, nunca reticulada. 
Nilsson et al. (1993) estudaram, dentre outros, os grãos de pólen de Forsteronia acouci (Aubl.) A. DC. e F. corymbosa (Jacq.) Meyer, caracterizando-os, principalmente, como 3-4-porados, oblatos, esferoidais ou com forma irregular, exina lisa, densamente perforada, com ânulus distinto, internamente granular ou mais ou menos liso. A única espécie de Forsteronia aqui analisada foi descrita como tendo exina escabrada no mesocolpo, com rúgulas conspícuas e perfurações próximo dos poros.

Não foram encontradas referências bibliográficas para a palinologia de Prestonia coalita e Rhabdadenia pohlii, no entanto, as duas espécies apresentam grãos de pólen semelhantes aos de Mandevilla e de Forsteronia. Os grãos de pólen de Prestonia coalita foram separados de Forsteronia leptocarpa, na chave aqui apresentada, pela sexina rugulada em toda a superfície na primeira espécie e escabrada no mesocolpo, rugulada próximo das aberturas em F. leptocarpa; os grãos de pólen de Rhabdadenia pohlii e Mandevilla sp. foram os únicos classificados como grandes (50-100 $\mu \mathrm{m})$.

A morfologia polínica de espécies de Tabernaemontana foi objeto de interesse de pesquisadores como Van Campo et al. (1979) e Nilsson (1986; 1990). Van Campo et al. (1979) estudaram a palinologia de 24 espécies do gênero e, dentre elas, Tabernaemontana flavicans que, segundo os autores, apresentou grãos de pólen 4-colporados, com dois colpos visíveis e uma zona equatorial contínua, exina fina, com grânulos na face interna. A característica comum em todas as espécies estudadas por Van Campo et al. (1979) foi a zona endoapertural contínua. Nilsson (1986; 1990) analisou os grãos de pólen de espécies pertencentes a 17 gêneros de Apocynaceae objetivando conhecer a variabilidade polínica da família. Nilsson (1986) analisou os grãos de pólen de quatro espécies de Tabernaemontana e em 1990, duas espécies, segundo o autor, foram caracterizadas por possuírem 3-4-cólporos, forma oblato-esferoidal a prolata, colpos curtos, endoaberturas lalongadas, podendo ou não estarem unidas formando uma faixa equatorial, exina perfurada. As duas espécies aqui estudadas apresentaram características distintas que permitiram a separação na chave e, apenas em T. flavicans a endoabertura é endocingulada; o número de cólporos variou (3-4-colporados em T. flavicans e 4-colporados em T. laeta); a exina mostrou-se rugulada. Os resultados aqui encontrados foram, de modo geral, semelhantes aos dos autores acima comentados.

As espécies brasileiras de Apocynaceae precisam de maior investigação no que diz repeito à morfologia polínica. Essa investigação é dificultada, talvez, pela fragilidade da parede dos grãos de pólen aos métodos de preparação. A família vinha sendo considerada estenopalinológica. Os resultados encontrados pelos autores anteriores e os do presente estudo, no entanto, mostraram uma certa variabilidade nas características polínicas que poderão ser usadas pelos taxonomistas para melhor delimitação das tribos e subfamílias.

\section{Referências bibliográficas}

Barroso, G.M.; Peixoto, A.L.; Ichaso, C.L.F.; Costa, C.G.; Guimarães, E.F. \& Lima, H.C. 1986. Sistemática de Angiospermas do Brasil. Impr. Universidade de Viçosa, Minas Gerais.

Barth, O.M. \& Melhem, T.S. 1988. Glossário ilustrado de palinologia. Ed. Unicamp, Campinas.

Cronquist, A. 1988. The evolution and classification of flowering plants. $2^{\text {nd }}$ ed. The New York Botanical Garden, New York.

Faegri, G. \& Iversen, J. 1964. Textbook of modern pollen analysis. $2^{\text {nd }}$ ed. Scandinavian University Books. Copenhagen.

Marques, M. \& Melhem, T.S. 1966. Pollen grains of plants of the "Cerrado" - XI. Apocynaceae. Anais da Academia Brasileira de Ciências 38(2): 371-378.

Novaes, J.R.C.; Rapoporte, B. 1996. In: Espécies coletadas no Estado do Rio de Janeiro depositadas no Herbário RB. M.C.M. Marques (ed.). Rio de Janeiro.

Nilsson, S. 1986. The significance of pollen morphology in the Apocynaceae. Pp. 359-374. S. Blackmore \& L.K. Ferguson (eds.). In: Pollen and Spores. Form and Function. Acad. Press, London.

Nilsson, S. 1990. Taxonomic and evolutionary significance of pollen morphology in the Apocynaceae. Plant System Evolution (Suppl. 5): 91-102.

Nilsson, S.; Endress, M.E. \& Grafstrom, E. 1993. On the relationship of the Apocynaceae and Periplocaceae. Grana (Suppl. 2): 3-21.

Punt, W.; Blackmore, S.; Nilsson, S. \& Le Thomas, A. 1999. Glossary of pollen and spore terminology. http:// www.biol.ruu.nl/ palaeo/glossary/glos-int.htm [acessado em 18 abr. 1999].

Raynal, A. \& Raynal, J. 1971. Une technique de préparation des grains de pollen fragilis. Adansonia 11(1):77-79.

Salgado-Labouriau, M.L. 1973. Contribuição à Palinologia dos Cerrados. Academia Brasileira de Ciências. Rio de Janeiro.

Van Campo, M.; Nilsson, S. \& Leeuwenberg, A.J.M. 1979. Palinotaxonomic studies in Tabernaemontana L. sensu lato (Apocynaceae). Grana 18: 5-14.

Wanderley, M.G.L. \& Melhem, T.S. 1991. Flora polínica da Reserva do Parque Estadual das Fontes do Ipiranga (São Paulo, Brasil). Família: 178-Bromeliaceae. Hoehnea 18(1): 5-42. 